\section{Os estereótipos, muito bem. Os imaginários, ainda melhor}

Les stéréotypes, c'est bien. Les imaginaires, c'est mieux

Patrick CHARAUDEAU (Universidade de Paris-Nord) patrick.charaudeau@free.fr

Traduzido por:

André Luiz SILVA (CEFET-MG) andre.alvaresesilva@gmail.com Rafael Magalhães ANGRISANO (CEFET-MG) rafaelangrisano@yahoo.com.br
CHARAUDEAU, Patrick. Os estereótipos, muito bem. Os imaginários, ainda melhor. Traduzido por André Luiz Silva e Rafael Magalhães Angrisano. Entrepalavras, Fortaleza, v. 7, p. 571-591, jan./jun. 2017.

\section{Tradução}

Tradução em português do original: CHARAUDEAU, Patrick. Les stéréotypes, c'est bien. Les imaginaires, c'est mieux. Disponível em: http://www.patrickcharaudeau.com/Les-stereotypes-c-estbien-Les,98.html. Acesso em: 17 de set. de 2017. 
v. 7 (1)

$571-591$

jan/jun

2017

Talvez não seja muito apropriado, em um colóquio que discorre sobre os estereótipos, começar por se desembaraçar desta noção. Mas diante de tantos escritos que lhe foram consagrados - sem que jamais ela fosse questionada ${ }^{1}$-, convém perguntar-se se esta é uma noção com a qual podemos trabalhar no quadro das ciências humanas e sociais, e, particularmente, na análise do discurso.

O que observamos? Primeiramente, que há uma proliferação de termos cobrindo um mesmo campo semântico: "clichês", "chavões", "lugares comuns", "ideias batidas", "preconceitos", "estereótipos", "lugar comum", para não citar mais. Pois há outras, como a expressão "velha ladainha", ouvida recentemente em uma emissão de rádio. Não se sabe ao certo que distinções estabelecer, e, ademais, a maior parte dentre eles são permutáveis.

Estes termos possuem certo número de traços semânticos em comum, já que dizem respeito àquilo que é dito de maneira repetitiva e que, de tal forma, termina por se sedimentar (recorrência e imutabilidade), e descreve uma caracterização julgada simplificadora e generalizante (simplificação). Por outro lado, esses termos circulam nos grupos sociais e o que eles designam é compartilhado por seus membros - desempenham, portanto, um papel de elo social (função identitária); mas, ao mesmo tempo, quando um destes termos é empregado, é para rejeitar a caracterização que descrevem, já que seria falso, extremamente simplista ou extremamente generalizante (julgamento negativo); alguns insistem mais sobre um ou outro desses aspectos: de falsa verdade ("ideias batidas"), de não verificação ("preconceitos"), de banalidade ("lugar-comum"), mas todos são portadores do traço da suspeita quanto à verdade do que é dito.

É a presença dessa suspeita que torna difícil a recuperação da noção de estereótipo para fazer dela um conceito. Primeiramente porque assinala que esta noção é dependente do julgamento de um sujeito, e que, sendo este julgamento negativo, oculta a possibilidade de que o que é dito contenha uma parte de verdade, a despeito de tudo. Esse mascaramento é ainda mais latente quando a caracterização concerne aos indivíduos ou grupos humanos: dizer que os intelectuais não gostam do exercício físico é talvez um estereótipo próprio dos esportistas, mas isso não significa que seja completamente falso; isso também se aplica aos julgamentos que os homens possuem sobre as mulheres e àqueles

${ }^{1}$ Certos escritos tentam uma hierarquização (Boyer, 2003), mas nenhum segmenta ou dispersa. 
que as mulheres possuem sobre os homens, àqueles que os cidadãos possuem acerca dos políticos e vice-versa. Em outras palavras, deve-se conceder ao estereótipo a possibilidade de dizer qualquer coisa de falso ou verdadeiro, simultaneamente. Todo julgamento acerca do outro é ao mesmo tempo revelador de si mesmo: diz, talvez, algo torpe sobre outro (refraçãoº), mas diz, ao mesmo tempo, algo de verdadeiro sobre aquele que pronuncia o julgamento (reflexão). Dizer que os franceses são cartesianos não é, evidentemente, verdade em seu absoluto; contudo, parte disso pode ser verdadeira e, sobretudo, esta é uma declaração reveladora daquele que a pronuncia, que se considera não cartesiano ou toma distância frente a esta caracterização.

Há, então, uma ambiguidade quanto ao uso que se faz dessa noção, inclusive nos escritos científicos que lhe foram consagrados: de um lado, defende-se a ideia de que o estereótipo tem uma necessária função de estabelecimento do elo social - a aprendizagem social se faria com a ajuda de ideias comuns repetitivas como garantias das normas do julgamento social; de outro, rejeita-se o estereótipo, já que ele deformaria ou mascararia a realidade. É bem difícil, nessas condições, tomar essa noção como central dentro da análise dos discursos sociais, salvo para assinalá-la como característica de certos fatos de discursos reveladores tal ou tal sujeito, dentro tal ou tal contexto situacional ${ }^{3}$.

\section{O que está envolvido?}

Essencialmente, duas coisas: a forma com que concebemos a conexão da linguagem à realidade e o lugar que damos ao fenômeno das representações sociais.

\section{Linguagem, "o real" e "realidade"}

A noção de "real" por muito tempo foi confundida com a de "realidade". Ou, na ordem do mundo empírico, ela remete aos objetos ou eventos do mundo fenomenal exteriores ao homem: o real, ou a realidade, se opõe, portanto, à aparência sensível das coisas (Platão), e designa o

\footnotetext{
${ }^{2}$ Esse termo provém da física da luz: um raio luminoso incidido sobre uma superfície aquosa se refrata no espaço aquoso, desviando seu ângulo de incidência, e se reflete a partir da superfície aquosa.

3 Já tive a oportunidade de verificar essa ambiguidade nas exposições de diferentes participantes do colóquio, que empregaram o termo de estereótipo, tanto para mostrar a falsidade de uma caracterização quanto para fazer um protótipo do julgamento social, assim como para descrever a imagem (ethos) que os sujeitos falantes constroem de si mesmos.
} 
v. 7 (1)

$571-591$

jan/jun

2017

dado autêntico de um mundo físico que existe independentemente do homem e se impõe a ele. Ou, considerado na ordem do pensamento, a realidade, ou o real, é vista como um objeto definido, lógico, permanente e autônomo; designadora de uma verdade sólida, um dado explicativo sobre o mundo como lei que se impõe ao homem, um tipo de "princípio de realidade".

Portanto, convém distinguir-se o real de realidade, e será a hipótese sobre o signo linguístico, na linha de Saussure e Benveniste, que nos ajudará para tal. Sabe-se que o signo, com sua dupla face significante/significado, caracteriza-se por uma tripla dimensão: referencial (remete a qualquer coisa do mundo), simbólico (constrói o sentido a partir deste mundo), contextual (adquire sentido dentro de uma ampla combinação contextual). Ele resulta da definição de que o significado não é a própria realidade, mas uma construção significante do mundo: se a palavra "árvore" remete a uma realidade empírica do mundo, ela constrói, por meio de tal língua, dentro de tal contexto cultural, o conceito árvore, como diria Saussure, ou seja, o real significante árvore dentro da língua portuguesa.

Generalizando o assunto, pode-se então dizer que "a realidade" corresponde ao mundo empírico através de sua fenomenalidade, como lugar a-significante (e ainda a-significado), impondo-se ao homem em seu estado bruto aguardando ser significada. Em oposição, "o real" refere-se ao mundo tal qual ele é construído e estruturado por atividade significante do homem por meio do exercício da linguagem em suas diversas operações de nominação dos seres do mundo, de caracterização de suas propriedades, de descrição de suas ações inseridas no tempo e no espaço e de explicação da causalidade dessas ações ${ }^{4}$. O real é, então, ligado à atividade de racionalização do homem, o que concorda, talvez, com a proposição de Hegel: "O que é racional é real, o que é real é racional", mas, evidentemente, acrescentando que o que é racional é, por si só, marcado pelo afeto e pelo emocional. A realidade sempre precisa ser "formatada" para tornar-se real, e esse trabalho de formatação se faz por meio da razão que, por sua vez, se faz por meio da linguagem: o real precisa remeter a uma razão, diz ainda Baudrillard, uma racionalidade que constrói oposições. Consequentemente, pode-se considerar que o discurso constrói sempre o real, e que o julgamento de

4 Para essas diversas operações, ver nosso artigo: Le fondement d'une Grammaire du sens à partir du modèle onomasiologique de Bernard Pottier, em Atas do colóquio em homenagem a Bernard Pottier (a ser publicado). 
verdade ou falsidade não tem lugar aqui; um determinado julgamento só pode ser um ato de linguagem, vindo se sobrepor ao ato de discurso construindo o real. O estereótipo aqui não tem razão de ser.

\section{As representações sociais como mecânica de construção do real}

Muitos escritos têm sido dedicados a essa noção, também na psicologia social, na qual ela surge dentro das análises do discurso ou sociolinguísticas. Resgatemos rapidamente sua emergência. Ela aparece em Durkheim sob a denominação de "representações coletivas", denominação esta contestada por Moscovici, uma vez que o termo de coletivo remete mais a um grupo fechado em si mesmo que às opiniões coletivas intracomunitárias. Moscovici propõe então a expressão "representações sociais", mais genérica, que inclui as representações coletivas sem o preconceito da escala de generalização da noção, uma vez que é necessário definir uma noção que explique e justifique as práticas sociais, suas normas e suas regras.

É como se o indivíduo não pudesse se contentar em agir, seria necessário dar-lhe uma razão para agir, motivos e finalidades que lhe permitissem possuir julgamentos sobre a legitimidade de suas ações; ele deve, então, representá-los em interações com os demais da língua, e, representando-os, ele se faz existir e inventa a sociedade, que o inventa ao mesmo tempo (ROUQUETTE, 1998). As representações sociais são, como consequência, um modo de tomar conhecimento do mundo socialmente partilhado.

Não entraremos aqui nos detalhes dessa noção assim como ela é desenvolvida pela psicologia social que, pelas necessidades de sua conceitualização, distingue as noções de "representação", de "opinião", de "atitude", de "sistema central" e de "sistema periférico" (GUIMELLI, 1999), mas lembraremos igualmente que Sperber e Wilson, em sua teoria da pertinência, falam de "representações partilhadas", noção fundadora da atividade da linguagem, que repousa sobre a ideia da adesão de membros de um grupo aos valores comuns, que seriam consenso para que pudessem se comunicar, ideia fortemente discutida por certos psicólogos (DOISE, 1985).

O que importa aqui, isto é, dentro do cenário da análise do discurso, é ver em que medida um conceito nascido e desenvolvido dentro de uma disciplina pode ser reutilizado e redefinido dentro de 
v. 7 (1)

$571-591$

jan/jun

2017

uma disciplina outras. De minha parte, retomarei, então, essa noção em sua definição, não como um conceito, mas como um mecanismo de construção do sentido que modela, formata a realidade em real significante, engendrando formas de conhecimento da "realidade social". Nessa perspectiva, as representações sociais não são um subconjunto dos imaginários ou das ideologias como outros propõem (BOYER, 2003, p. 19), mas uma mecânica de engendramento dos saberes e dos imaginários, como veremos a seguir ${ }^{6}$.

\section{Proposição: uma definição discursiva dos imaginários}

O termo do imaginário cria também um problema, não apenas em razão do sentido que adquire em seu uso corrente, mas também pela forma com que é empregado em certas disciplinas.

\section{A noção de imaginário}

Em seu uso corrente, o termo de imaginário é empregado no sentido daquilo "que existe apenas na imaginação, que não tem realidade", como define o dicionário Robert (1990). E esse sentido é, por vezes, aplicado a uma pura invenção de espírito que descreve qualquer coisa que não possui correspondente na realidade e que, portanto, não é verdade. Nesse caso, lhe são dados como sinônimos os termos de mito, lenda, ficção, e, frequentemente, é portador de um julgamento negativo, como em "É uma doença imaginária". Por vezes o sentido de base é aplicado em uma construção idealizada, tendo às vezes o sentido de ilusão, mas não necessariamente negativo: "um mundo imaginário", que pode ser uma utopia ou um sonho não realizável.

Nos meios artísticos e literários, imaginário é empregado para qualificar a atividade artística em seu fundamento, sem conotação pejorativa, uma vez que admite-se que a função do artista é a de propor uma visão de um mundo outro, o qual aceitamos não corresponder à realidade, mas que pode ser pressagiador, anunciador de um próximo mundo real: "O imaginário é o que tende a se tornar real" (André Breton). Todo artista é um visionário.

Mas em outras disciplinas das ciências humanas e sociais,

\footnotetext{
5 Ao que chamo de "interdisciplinaridade focalizada", ver: La justification d'une approche interdisciplinaire de l'étude des médias, em Atas do colóquio de Lausanne (a ser publicado).

${ }^{6}$ Ver também nosso Le discours politique. Les masques du pouvoir (2005b).
} 
posta à parte a Antropologia, da qual nos apropriaremos de uma parte da definição, o emprego não é sempre muito claro. Em História, por exemplo, ouve-se dizer, às vezes, que é uma disciplina com vocação para restabelecer a verdade, contrária ao imaginário, aos fantasmas e aos estereótipos ${ }^{7}$. Esse sentido, finalmente pejorativo ao ver de certas disciplinas, é talvez um resquício do pensamento do século XVIII, que distinguia uma cultura científica de uma cultura popular, estas fortemente influenciadas pelas histórias de demônios e bruxaria.

Parece, assim, que nos encontramos na mesma situação de quando tratávamos dos estereótipos, e, então, deveria se rejeitar essa noção pelas mesmas razões. Mas aqui, podemos tomar o caminho do emprego desse termo como substantivo, uma vez que é em seu emprego como adjetivo que adquire esses valores de invenção excluída da realidade. Em contraste, em seu emprego como substantivo, "imaginário" recupera uma noção que se inscreve em uma tradição filosófica e psicológica, para ser finalmente recuperada e reconceitualizada pela antropologia social.

Resumidamente, digamos que a emergência de tal noção se faz em três tempos. No pensamento clássico, a imaginação era considerada como fantasia, estava ao lado da loucura ("a loucura da lógica"), que se opunha, por sua vez, à razão, a única capaz de gerar a confrontação frente a frente entre o Homem e o Mundo. Pensamento clássico que permaneceu até o século XVIII, o segundo grande momento, com Freud e a afirmação da existência de uma dupla consciência do homem, dupla consciência que se cruza com a dualidade de um "ego individual" e de um "ego coletivo". No segundo tópico ("Id, Ego e Superego"), Freud coloca o Imaginário ao lado do "Superego", o "Id" sendo da ordem do Simbólico. Imediatamente depois, Jung desenvolveu sua ideia de "arquétipos" como um conjunto de temas recorrentes que construiria os imaginários pessoais sobre um fundo comum de inconsciente coletivo. Paralelamente, Bachelard (eles são quase contemporâneos) opõe a "conceitualização", atividade racionalizante produtora da ciência, e o "devaneio", atividade criativa produtora de uma visão poética do mundo; mas ambas as atividades ligadas, por aquilo que são, à origem dos princípios organizadores de condutas humanas. O terceiro grande momento é marcado pela antropologia, que considera os rituais sociais, os mitos e as lendas como discursos que refletem a organização das

$7 \mathrm{Na}$ emissão Concordance des temps, na France Culture, Jean Noël trata de: "as estações, lugares de todos os imaginários e fantasmas". 
v. 7 (1)

$571-591$

jan/jun

2017

sociedades humanas. É nessa linha que me colocarei para redefinir a noção de imaginário no quadro da análise do discurso.

\section{Os imaginários sócio-discursivos}

O imaginário é uma forma de apreensão do mundo que nasce na mecânica das representações sociais, a qual, conforme dito, constrói a significação sobre os objetos do mundo, os fenômenos que se produzem, os seres humanos e seus comportamentos, transformando a realidade em real significante. Ele resulta de um processo de simbolização do mundo de ordem afetivo-racional através da intersubjetividade das relações humanas, e se deposita na memória coletiva. Assim, o imaginário possui uma dupla função de criação de valores e de justificação da ação. Por exemplo, o imaginário da Modernidade cria tanto valores negativos - quando, opondo-se àqueles da Tradição, estigmatiza a perda do peso da história, da herança do passado e dos benefícios da filiação - quanto valores positivos - quando, ligada ao Progresso, se define como um desafio permanente às leis da natureza e um aumento do bem-estar social através dos avanços tecnológicos.

Esse imaginário pode ser qualificado de social à medida que esta atividade de simbolização representacional do mundo se faz dentro de um domínio de prática social (artística, política, jurídica, religiosa, educativa, etc.) determinado, de forma a, como propõe Castoriadis, tornar coerente a relação entre a ordem social e as condutas, e cimentar o elo social com a ajuda dos aparelhos de regulação que são as instituições. Mas deve-se acrescentar que o imaginário social é de dimensão variável, devido à maior ou menor extensão do grupo, do jogo de comparação possível entre grupos, e da memória coletiva do grupo que se constrói através da história. Assim, podemos falar de um imaginário pessoal, como no caso da percepção da morte; a qual será julgada e experienciada diferentemente, dependendo de estar inserida na história íntima do indivíduo (a morte de um parente ou de alguém próximo ${ }^{8}$ ), de tocar um sentimento de pertencimento comunitário (morte de Israelenses pelos Israelenses, morte de Palestinos pelos Palestinos) ou de um valor considerado como uma evidência moral universalmente compartilhada (a morte dos inocentes, especialmente se tratando de crianças). Mas há também os imaginários mais propriamente coletivos, que variam segundo a natureza do grupo. Por exemplo, cada uma de

${ }_{8}^{8}$ Poderia mesmo ser um animal para seu mestre ou mestra. 
ambas as leis defendidas no Parlamento francês - a dita Lei Taubira, que reconhece a escravidão como crime contra a humanidade, e a Lei Gayssot, que reconhece os aspectos positivos da colonização francesa - pertence a imaginários diferentes. A primeira se identifica com o imaginário de "soberania popular", que afirma a igualdade dos cidadãos perante a lei e, portanto, condena toda discriminação contra parte da cidadania; a segunda remete a um imaginário de "excelência da cultura", que justificaria toda ação educativa sobre um povo julgado alheio aos valores que se quer imprimir-lhe. E notemos que tanto um quanto outro desses imaginários se sustentam na crença em seu valor universal. É o que explica a emergência de conflitos, como o que eclodiu após a publicação de charges do profeta Maomé, deslanchando uma polêmica que evidenciava um antagonismo entre Oriente e Ocidente quanto ao que pode ser o imaginário do "sagrado" dentro de uma e de outra cultura.

Enfim, esse imaginário pode ser qualificado de sócio-discursivo na medida em que se cria a hipótese de que o sintoma de um imaginário é a fala. De fato, ele resulta da atividade de representação que constrói os universos de pensamento, lugares de instituição de verdades, e essa construção se faz por meio da sedimentação de discursos narrativos e argumentativos, propondo uma descrição e uma explicação dos fenômenos do mundo e dos comportamentos humanos. Ele se constrói, assim, de sistemas de pensamento coerentes a partir de tipos de saber que são investidos, por vezes, de pathos (o saber como afeto), de ethos (o saber como imagem de si) ou de logos (o saber como argumento racional). Logo, os imaginários são engendrados pelos discursos que circulam nos grupos sociais, se organizando em sistemas de pensamento coerentes, criadores de valores, desempenhando o papel de justificação da ação social e se depositando na memória coletiva.

Mas a isso deve-se acrescentar que esses discursos criadores de imaginários se produzem, como já dito, dentro de um domínio de determinada prática social que desempenha um papel de filtro axiológico. Isso permite compreender que um mesmo imaginário possa receber um valor positivo ou negativo, dependendo do domínio de prática no qual se insere. Assim, o imaginário de Tradição será marcado de maneira positiva no domínio de prática religiosa e, por vezes, no da política, enquanto será marcado negativamente nos domínios econômico e tecnológico. Evidentemente, tomamos aqui o valor intrínseco dado ao imaginário e não a maneira com que é utilizado. O imaginário do 
v. 7 (1)

$571-591$

jan/jun

2017

"direito à liberdade" pôde justificar os compromissos da resistência durante a Segunda Guerra Mundial, mas foi o imaginário da "pureza dos povos" que se mostrou fonte, na história, de extorsões, massacres e genocídios.

Ilustremos isso com dois exemplos. Os pássaros, primeiramente, que são percebidos através de diversos imaginários, cujos sintomas são os discursos produzidos a seu respeito, seja para descrevê-los, seja para qualificá-los, seja imaginando suas intenções: imaginário de "morte ou de ameaça", quando são negros ${ }^{9}$ (corvos) ou quando se precipitam sobre a carne fresca (urubus); imaginário de "amor" (codornas) ou de "fidelidade" (pombos), mas também de "luxúria" ou de "perversidade" (perdizes), quando não se deixam ser pegos e enganam aqueles que tentam agarrá-los ${ }^{10}$; imaginário de "vigilância" e de "inteligência", como os gansos do Capitólio que evitaram o massacre da população de Roma, mas sem esquecer que os gansos pertencem igualmente ao imaginário da "tolice" ou da "ingenuidade" (tolo como um ganso branco). Outro exemplo: o corpo. O médico, examinando-o, tateando-o, apalpando-o, produz um discurso que o torna um lugar de aparição de sintomas: é o imaginário médico de "traço" ou de "indicialidade" como pesquisa de uma significação escondida sob a manifestação de um signo. Mas o biólogo considera o corpo através de um imaginário "tecidual" e "celular", e o psicanalista o considera como um lugar de "somatização".

\section{A estruturação dos imaginários}

Resumindo o conjunto de proposições anteriores, podemos dizer que a mecânica das representações sociais gera, através da produção de discursos, os saberes que se estruturam em saberes de conhecimento e saberes de crença, os quais se configuram, por sua vez, em tipos de saberes. É a partir desses tipos de saberes, e sempre por meio da produção discursiva, que se organizam os sistemas de pensamento conforme os princípios de coerência que criam teorias, doutrinas ou opiniões. Depois de já ter exposto essa questão em outros escritos ${ }^{11}$, retomarei uma parte, fornecendo alguns detalhes adicionais.

\footnotetext{
${ }_{9}$ Nas culturas onde o negro evoca o imaginário de morte.

${ }^{10}$ Ver os contos e as fábulas.

${ }^{11}$ Ver, particularmente, Les non-dits du discours (2005a).
} 


\section{Os saberes de conhecimento}

Os saberes de conhecimento tendem a estabelecer uma verdade sobre os fenômenos do mundo. Uma verdade que existe fora da subjetividade do sujeito, ou que ao menos foi instalada no exterior do homem (off topic). Essa verdade repousa na existência dos fatos do mundo e na explicação dos fenômenos que são colocados frente ao homem e postos à sua consideração, em uma relação objetivante e enunciados sob a forma de um "ele-verdadeiro", da parte de um sujeito da enunciação que se quer neutro, sem julgamento, desprovido de toda subjetividade, um enunciador abstrato, impessoal, podendo chamar-se "a ciência" ou "a ordem das coisas", cuja garantia é a possibilidade de verificação das proposições necessárias e, portanto, do saber. O discurso assim produzido não é ponto discutível, uma vez que se impõe sobre a verdade objetiva.

Esse processo de construção do saber de conhecimento dá lugar a dois tipos de saberes: o saber científico e o saber de experiência.

O saber científico constrói explicações sobre o mundo que se aplicam ao conhecimento do mundo tal como ele é e funciona. Estáse na ordem da razão científica, que se baseia nos procedimentos de observação, de experimentação e de cálculo, os quais se utilizam de instrumentos de visualização do mundo (microscópio) ou de operações (informática), e cuja garantia objetivante é a de que esses procedimentos e esses instrumentos podem ser seguidos e utilizados por qualquer pessoa com a mesma competência. Está-se aqui na ordem do provado. Ninguém jamais viu a terra girar em torno do sol. Contudo, temos esse conhecimento, pois tomamos conhecimento de tal como saber científico, provado de maneira indiscutível.

Podem ser ligadas ao saber científico aquilo que chamamos de teorias. As teorias se caracterizam por uma forma de discurso que é ao mesmo tempo fechada e aberta. Fechada em torno de um núcleo de certezas constituído por um conjunto de proposições com valor de postulados, de princípios ou de axiomas, dos quais dependem os conceitos, os modos de raciocínio e a aparelhagem metodológica. Aberta na medida em que essa forma de discurso se encontra em um processo de refutação/integração de proposições contrárias ou de resultados contraditórios. Ou seja, as teorias são obrigadas a aceitar a confrontação com o empirismo e a crítica. Mas no momento em que a teoria se enuncia como tal, ela tem a força de verdade de um discurso demonstrativo, como é o caso, por exemplo, das leis da gravidade. 
v. 7 (1)

571-591

jan/jun

2017

O saber de experiência, por sua vez, constrói igualmente explicações sobre o mundo que se aplicam ao conhecimento do todo, mas sem nenhuma garantia de serem provadas: não possui procedimentos particulares nem instrumentos. Pelo contrário, todo indivíduo pode se valer de um saber de experiência desde que o tenha experimentado e que possa supor que qualquer outro indivíduo na mesma situação tenha experimentado a mesma coisa: se eu solto um objeto que tenho na mão, terei a experiência de que ele cairá todas às vezes, e suporei que qualquer outra pessoa no mesmo lugar e espaço terá a mesma experiência. Estamos aqui no domínio do experienciado e da experiência universalmente partilhada, e não preciso, por isso, do saber científico: não preciso conhecer as leis da gravidade para saber que se solto um objeto, ele cairá. Não obstante, manterei esse saber de experiência para conhecer o mundo tal como ele é.

Serão, portanto, atrelados a esse saber de experiência os saberes empíricos sobre o mundo, que são sustentados por um discurso de causalidade natural, mesmo que contradiga o saber científico: continuamos a dizer que o sol se levanta e se põe (saber de experiência), mesmo que saibamos que é a Terra que gira e não o sol (saber científico). Essas são as duas formas de saber de conhecimento, já que ambas tomam o que é dito pelo que é o mundo (não nos esqueçamos de que nos encontramos aqui no domínio das representações sócio-discursivas).

\section{Os saberes de crença}

Os saberes de crença não se relacionam com o conhecimento do mundo no sentido que temos que atribuir a ele, mas com as avaliações, apreciações, julgamentos a respeito dos fenômenos, dos eventos e dos seres do mundo, seu pensamento e seu comportamento. O conhecimento, como acabamos de ver, procede de um modo de descrição ou de explicação centrado no mundo, independentemente do ponto de vista do sujeito: a crença procede do olhar que o sujeito tem sobre a legitimidade dos eventos e das ações do homem. Aqui, não é a questão de ter um ponto de vista sobre a Terra que gira, uma vez que essa é uma explicação que me foi dada por um saber científico indiscutível; é a questão de saber se, por exemplo, é preferível trabalhar ao nascer do sol ou ao por do sol, se é bom, mal, razoável ou louco dirigir sob uma tempestade, se é bom ou mal entrar em tal conflito. O saber, aqui, se encontra no sujeito, procede do sujeito (in-sujeito), e é portador de julgamento. Estamos 
no domínio do valor, que se caracteriza, ao mesmo tempo, por ser uma atividade mental polarizada entre a razão de ser dos eventos e dos comportamentos (daí seu aspecto afetivo) e por um posicionamento (daí seu aspecto subjetivante). Já não tratamos mais da enunciação de um "ele-verdadeiro", mas sim de um "nós-verdadeiro", que interioriza o saber e ao mesmo tempo o deseja compartilhado, ainda que, nesse caso, não ele não seja verificável - outra diferença com relação ao saber de conhecimento, ainda que por vezes seja difícil diferenciá-los.

Esse processo de construção do saber de crença dá lugar a dois tipos de saber: o saber de revelação e o saber de opinião.

O saber de revelação supõe a existência de um lugar de verdade exterior ao sujeito, mas, diferentemente do saber de conhecimento, essa verdade não pode ser provada nem verificada, isso porque ela exige um movimento de adesão total do sujeito a ela. Mas para que esse movimento de adesão encontre sua justificação, devem existir textos que testemunhem essa verdade mais ou menos transcendental. De uma forma ou de outra, esses textos têm um caráter sagrado, desempenhando o papel de referência absoluta dos valores aos quais se quer aderir.

Não é, portanto, surpreendente que sejam as doutrinas que se atrelem a esse tipo de saber, doutrinas ditas religiosas ou profanas. As doutrinas se definem na referência a uma palavra fundadora, emanando, na maior parte das vezes, de uma figura carismática (o poeta na Grécia Antiga, o profeta nas religiões cristãs, o guru nas seitas, o fundador de uma escola de pensamento). Se as doutrinas têm um caráter fechado como o das teorias, as primeiras, diferentemente das segundas, não sofrem questionamentos e se estabelecem como dogmas. As doutrinas são insensíveis às contradições nas quais poderiam cair os saberes científicos ou de experiência. Esses últimos são fechados, mas "até que se prove o contrário", até que uma nova teoria venha substituir a precedente ou que uma nova experiência venha contradizer a precedente: os saberes de conhecimento são ao mesmo tempo fechados e abertos. O saber de revelação, pelo contrário, é completamente fechado sobre uma evidência de saber, e o discurso que o sustenta se apresenta sob a modalidade da evidência. Ele recusa a crítica, e, frente a ela, só pode reagir por meio de anátemas, excomunhões ou outras formas de exclusão. Enunciados como "Jesus é o filho de Deus feito homem" ou "Amai-vos uns aos outros" referem-se a uma verdade revelada, que só pode ser oposta pela negação da palavra de revelação, a negação da fé nessa palavra. Mas o mesmo se passa com enunciados de valor 
v. 7 (1)

$571-591$

do tipo "O povo é soberano" ou "Liberdade, igualdade, fraternidade". Enquanto pertencente ao saber de crença, estamos no domínio do "nósverdadeiro", uma vez que esse exige adesão da parte do sujeito, mas um nós-verdadeiro que queira substituir o "ele-verdadeiro" do saber de conhecimento.

É a esse tipo de saber de revelação que se podem atrelar as ideologias. Mas, evidentemente, tudo depende da maneira com a qual se define esse conceito. A psicologia social, por exemplo, considera que "ideologia é uma noção que permanece relativamente imprecisa, sem verdadeira consistência teórica, na qual se fazem entrar formas de expressão extremamente variadas, tais como as crenças ou as teorias (ingênuas ou filosóficas), os valores ou as imagens, as normas ou as maneiras particulares de percepção da realidade..." (GUIMELLI, 1999, p. 105). De fato, as ideologias articulam de maneira doutrinária os saberes genéricos que propõe uma explicação total e englobante da atividade social, enquanto dependem dos discursos a que fazem referência, e, por trás dos quais, percebemos por vezes um pensador mais ou menos "baliza". De fato, uma ideologia é sempre mais ou menos imprecisa (o que pode, de qualquer modo, garantir seu sucesso), e quando seu discurso se endurece e se fixa em um texto de referência mais ou menos sagrado, ela tende a se tornar doutrina. Assim foi com o marxismo, que, se era em sua origem uma teoria, tornou-se uma ideologia de tendência doutrinária e dogmática.

Os saberes de opinião nascem de um processo de avaliação do termo sobre o qual o sujeito toma partido e se engaja em um julgamento a respeito dos fatos do mundo. Como no saber de crença, nele não é o mundo que se impõe ao sujeito, mas o sujeito que se impõe ao mundo, o que marca bem a diferença entre "Faz frio" e "Tem que pôr um agasalho". Mas aqui, não há um discurso de referência absoluto e, portanto, nos encontramos em um universo de saber onde se deve admitir que existem inúmeros julgamentos a respeito dos fatos do mundo, julgamentos dentre os quais o sujeito faz uma escolha segundo diversas lógicas: do necessário, do provável, do possível, do verossímil, e nos quais mais intervém a razão que a emoção. A opinião resulta de um movimento de apropriação, da parte de um sujeito, de um saber dentre os saberes circulantes nos grupos sociais. Esse saber é, então, ao mesmo tempo pessoal e partilhado, e é por isso que não pode ser discutido. E, mesmo quando aparece sob uma enunciação generalizante, como no caso dos provérbios, máximas e ditados, o sujeito sabe que esse saber 
é discutível, como prova o fato de que a todo provérbio responde um contraprovérbio. Está sempre em questão um julgamento de verdade por trás do qual se encontra um ver geral, uma crença popular anônima, como que emanando de uma voz que se encontra por sobre os sujeitos (um metaenunciador); de modo algum uma voz da razão ou da ciência, mas uma voz coletiva em relação à qual o sujeito se posiciona. Quando esse sujeito enuncia "Os vinhos de Bordeaux são verdadeiramente superiores aos vinhos de Bourgogne" ou "Quando você é Ministro, ou você se cala ou você se demite", ele sabe que exprime um ponto de vista que pode ser contradito; e se uma discussão se encadeasse a respeito dessas proposições, seria baseada em posições tomadas à luz do que cada um acredita ser verdade de seu ponto de vista. Todo julgamento de opinião é subjetivo enquanto depender de ser partilhado, isso porque assume ao mesmo tempo uma função identitária (a qual não tem necessariamente o saber de conhecimento).

A esse tipo de saber podem ser atreladas diversas categorias de opinião a que chamaremos: opinião comum, opinião relativa e opinião coletiva. A opinião comum tem um escopo generalizante, que se quer mesmo universal a qual se espera que seja largamente partilhada. Independentemente da forma de exprimi-la, o sujeito que a enuncia diz qualquer coisa como "Eu penso como todo mundo que..." ou "Todo o mundo pensa que... e eu também". É a opinião expressa pelos provérbios, ditados e outros enunciados de valor geral:

"Melhor é ser belo e rico que feio e pobre". Encontramos esse tipo de opinião nos slogans publicitários ou políticos: "Só Maille [marca tradicional de mostarda Dijon] me vai bem", "A força tranquila", e em certos comentários jornalísticos: "A guerra é fonte de miséria". Com a opinião comum, o sujeito falante não reivindica uma posição particular, pois se apropria do julgamento da crença popular.

A opinião relativa tem um aporte mais limitado, por emana de um sujeito individual ou de um grupo restrito. Mas esse sujeito ou os membros do grupo sabem que esse julgamento é circunstancial, relativo ao grupo e à situação na qual ele é emitido. Isso porque, nesse caso, o sujeito falante precisa afirmar, frente a frente com essa opinião, seja sua adesão, seja sua oposição, uma vez que, como existem diversas, esta se presta obrigatoriamente à discussão. A opinião relativa se inscreve desde seu surgimento em um espaço de discussão, não no interior do grupo, mas frente a frente com outros grupos. Ela é, em seu fundamento, crítica. O sujeito que emite uma opinião relativa diz 
v. 7 (1)

571-591

jan/jun

2017

qualquer coisa como "Eu penso como (e/ou contra) esses (alguns) que pensam que...". Está sempre, necessariamente, contra ou a favor de outra opinião, ela própria relativa: "Eu penso que a Europa é uma boa coisa para a França" deixa a entender que há outros que têm uma opinião contrária. A opinião relativa é aquela que se exprime no espaço da discussão da democracia.

A opinião coletiva é a que um grupo exprime a respeito de outro grupo. Ela consiste em confinar o outro grupo a uma categoria definitiva em seu essencial. Se se diz "Os espanhóis são orgulhosos", carregase um julgamento sobre os espanhóis enquanto grupo essencializado, ao passo que se deixa entender que se pertence a um grupo que não possui essa característica. Se for dito: "Os espanhóis pensam que os franceses são chauvinistas", é como se fosse dito que esse julgamento é próprio aos espanhóis e somente a eles, que deve nascer-se espanhol para se possuir tal opinião. Tanto em um caso quanto no outro, está em questão uma opinião de forte valor identitário, que não se discute e que essencializa um grupo. À época do Referendo sobre a Constituição europeia, ouvimos serem expressas opiniões coletivas essencializantes sobre a Turquia, fosse para rejeitá-la, fosse para integrá-la.

É desses tipos de saberes que se alimentam os imaginários, evidentemente, jogando muitas vezes com essas categorias, apagando as pistas, fazendo passar um saber de crença por um saber de conhecimento, um saber de opinião por um saber de revelação, introduzindo um saber de opinião relativa com o papel de um saber de opinião comum, transformando um saber teórico em saber de doutrina (o Marxismo), fazendo crer que um saber de revelação é também fundado em saber científico (as seitas). Daremos como exemplo a maneira com que a questão da clonagem foi tratada pela imprensa francesa ${ }^{12}$, essa questão participando de um imaginário da "reprodução do mesmo ao infinito". Certos especialistas apresentaram argumentos relativos aos saberes de conhecimento científico: "É necessário distinguir-se a clonagem reprodutiva, que afeta o embrião, da clonagem terapêutica, só afeta as células mães", ao que se opuseram os cientistas: "Todo geneticista sério sabe que não se pode separar o embrião das células tronco"; as autoridades religiosas apresentaram argumentos relativos aos saberes de crença instituídos em doutrina: "Não podemos aceitar a clonagem, qualquer que seja sua forma, pois toca no que a vida tem de mais

${ }^{12}$ A partir de uma pesquisa sobre o discurso de mediação científica realizado pelo Centro de Análise do Discurso da Universidade de Paris XIII (não mais publicado). 
sagrado e que não pertence ao homem: a procriação"; diversos autores, pensadores, políticos, responsáveis de associações se afrontaram com argumentos relativos aos saberes de opinião comum: "a clonagem terapêutica fará avançar a pesquisa medicinal" / "a clonagem terapêutica necessariamente deslizará em direção à clonagem reprodutiva, como já vimos no passado" ou bem "A clonagem reprodutiva trará problemas de identidade em termos de filiação do indivíduo" / "Mas a filiação já é prejudicada em nossas sociedades modernas". Vê-se como um imaginário tocante à identidade do homem é alimentado por diversos tipos de saberes.

\section{Problemas e questões}

Compreendamos: nossa proposição consiste em se desfazer de uma noção, o estereótipo, que é demasiado restritiva, uma vez que só é identificada por seu caráter de fixação de uma verdade que não seria provada ou que seria falsa. O imaginário não é nem verdadeiro nem falso. Ele é uma proposição de visão do mundo que se baseia nos saberes que constroem os sistemas de pensamento, os quais podem se excluir ou se sobrepor uns aos outros. Isso permite ao analista não ter que denunciar este ou aquele imaginário como falso. Não é esse seu papel. Seu papel consiste em ver como aparecem os imaginários, em qual situação comunicativa eles se inscrevem e qual visão de mundo eles testemunham. Em lugar de dizer que "Os franceses são sujos" é um estereótipo fabricado por certas comunidades alheias aos franceses, constatar que no imaginário da "limpeza/sujeira" se constroem pontos de vista, acerca dos quais se devem analisar os saberes sobre os quais se apoiam através dos discursos que são produzidos no interior de cada comunidade emissora desse julgamento. Descobriremos então que os discursos e os tipos de saberes diferem de uma comunidade à outra, revelando ao mesmo tempo características identitárias dessas mesmas comunidades $^{13}$.

Resta que, acerca dessa noção de imaginário, certas questões devem ser objeto de aprofundamento. Levantaremos rapidamente duas delas.

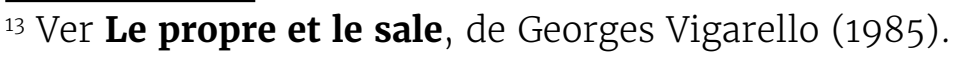


v. 7 (1)

571-591 jan/jun 2017

\section{A determinação do conteúdo dos imaginários}

Determinamos dois grandes tipos de saberes, mas deve-se ainda precisar seu conteúdo a partir da análise dos discursos produzidos. Ora, a dificuldade reside no fato de que esses conteúdos se constroem do cruzamento de diversos universos de discursos.

Há universos de discursos que correspondem aos "domínios da prática social": aqueles do político, do científico, do religioso, do educativo, do jurídico, etc. Foi dito que os domínios de prática social desempenham o papel de filtros construtores dos saberes e, portanto, dos imaginários. Cada um, então, engendra saberes e imaginários que lhe são próprios, mas, ao mesmo tempo, estes podem circular de um domínio ao outro: o imaginário da Tradição, como vimos, é dotado de um valor diferente conforme se inscreva no domínio da prática de economia ou de política.

Há universos de discursos que se constroem a partir de "experiências culturais" da vida: são os que concernem à língua e seu papel identitário, o espaço-tempo e seu papel organizacional, a alimentação e seu papel de princípio vital, a morte e seu papel de determinação do destino e, ainda, o trabalho, o clima, etc.

Há o que podemos chamar de "universos nocionais" de explicação sobre o mundo e a vida em sociedade, os tópicos: o progresso, a arte, a modernidade, a tradição, a democracia, o poder, a solidariedade, a liberdade, etc.

No mais, desses universos são criadas axiologias de diversas maneiras, dependendo dos "domínios de valor" que colocam em jogo os julgamentos específicos: o domínio ético que cria a axiologia do o Bem e do Mal, o domínio estético que cria a axiologia do Belo e do Feio, o domínio hedônico que cria a axiologia do Prazer e do Desprazer, o domínio epistêmico que cria a axiologia do Crer verdadeiro e do Crer falso.

Assim o imaginário do "sucesso" não será concebido da mesma forma em um domínio de prática política, educativa ou econômica, ele cruzará as experiências de vida da língua ou do trabalho, será alimentado pelos tópicos do progresso ou do poder e sua axiologia criada diferentemente segundo um domínio de julgamento ético, estético ou hedônico. 


\section{Os níveis de interpretação}

É uma das questões mais delicadas de se tratar, a questão de saber em qual nível de generalidade ou de profundidade se situam os imaginários. Entrecruzam-se aqui dois parâmetros. Aquele do contexto - sociocultural, cultural ou antropológico -, com aquele do nível da consciência coletiva: inconsciente, não consciente ou consciente. Muitos antropólogos estão atrelados à ideia, e particularmente Gilbert Durand ${ }^{14}$, que propõe a noção de "trajeto antropológico", apoiando-se no segundo tópico de Freud. Haveria um "id antropológico" correspondente a um nível de inconsciente coletivo onde se encontram imagens arquetípicas estáveis, um "superego imaginário", lugar de instituição de regras, códigos e leis da sociedade, e, entre os dois, um "eu social", no qual o indivíduo joga com os papéis sociais e as máscaras do jogo social. Assim, os imaginários circulariam entre três polos. A ideia é sedutora, mas o analista do discurso não tem os meios de se dotar de critérios que permitiriam classificar os imaginários em níveis. Pelo contrário, relacionando diversos tipos de discursos circulantes, apoiandose na interdiscursividade, ele pode tentar articular diversos tipos de imaginários, os quais sinta se situarem em níveis diferentes.

Por exemplo, retomando a questão da clonagem, e para concluir, podemos operar inúmeros paralelos. O imaginário da "clonagem como a reprodução do mesmo ao infinito" é configurado semiologicamente e discursivamente dentro do domínio econômico, os produtos do mercado são reproduzidos identicamente, dando a ilusão ao consumidor de que é a demanda que comanda a oferta (enquanto dá-se o contrário), e que ele pode adquirir a preços menores o mesmo produto que, de luxo, é reservado aos ricos. Esse fenômeno de reprodução dos produtos mercadológicos se faz do entrecruzamento do imaginário da clonagem com o da promoção social. É o discurso publicitário que o coloca discursivamente em cena.

Mas podemos estabelecer outro cruzamento dos imaginários mais enterrado na memória coletiva. Poderemos observar que o cinema americano contemporâneo coloca em cena, à exaustão, esse fenômeno de reprodução: reproduções de robôs e outros clones, renascimento idêntico ao que fora destruído, o vilão indestrutível que nunca deixa de retornar quando o cremos definitivamente eliminado. Se colocarmos em paralelo o debate social sobre a clonagem terapêutica e reprodutiva,

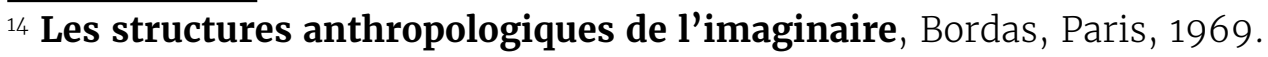


v. 7 (1)

$571-591$ jan/jun 2017

podemos encontrar um ponto em comum em torno de um imaginário de "morte e de sua conjuração": a angústia frente ao desaparecimento de si, frente à fatalidade, frente ao destino, que engendra as figuras de perpetuação de si próprio. E, vasculhando um pouco mais longe no passado discursivo, podemos operar um paralelo com o mito de Prometeu, que foi condenado por Zeus a ter seu fígado devorado por um pássaro - fígado reconstituído sem cessar - por ter dado o fogo à humanidade. A clonagem reprodutiva seria esse desafio lançado a Deus, aos deuses ou ao Destino, de apropriação do poder de se perpetuar. Aqui estamos em pleno imaginário "prometeico", imaginário este que não é nem um pouco distante do imaginário da "desobediência", desobediência de Satã, anjo decaído, desobediência de Adão e Eva, expulsos do Paraíso. Nos dois casos, desobediência por ter desejado se apropriar do Conhecimento, ato de usurpação de poder.

Aí está onde podemos conduzir a análise do discurso dos imaginários. Em todo caso, muito além dos estereótipos.

\section{Referências}

AMOSSY, R.; HERSCHBERG PIERROT A. Stéréotypes et clichés. Paris: NathanUniversité, 1997.

BOYER H. De l'autre côté du discours. Recherches sur les représentations communautaires. Paris: L'Harmattan, 2003.

CHARAUDEAU P. (Dir.). Les non-dits du discours. Paris: L'Harmattan 2005a.

CHARAUDEAU P. Le discours politique. Les masques du pouvoir. Paris: Vuibert, 2005b.

CHARAUDEAU P. La justification d'une approche interdisciplinaire de l'étude des medias. In: ACTES DU COLLOQUE DE LAUSANNE (a publicar).

CHARAUDEAU P. Le fondement d'une Grammaire du sens à partir du modèle onomasiologique de Bernard Pottier. In: ACTES DU COLLOQUE EN HOMMAGE À BERNARD POTTIER (a publicar).

DOISE W. Les représentations sociales: définition d'un concept. Revue Connexion, n. 45, Paris, 1985.

DURAND G. Les structures anthropologiques de l'imaginaire. Paris: Bordas, 1969.

GUIMELLI C. La oensée sociale. Paris: PUF, 1999.

PLANTIN C. (Dir.). Lieux communs. Topoï, stéréotypes, clichés. Paris: Kimé, 1993. 
ROUQUETTE M-L.; RATEAU P. Introduction à l'étude des représentations socials. Grenoble: PUG, 1998.

VIGARELLO G. Le propre et le sale. L'hygiène du corps depuis le Moyen Age. Paris: Le Seuil, 1985.

Recebido em: 11 de fev. de 2017.

Aceito em: 12 de jun. de 2017. 